\title{
Silk Abscission in Two Sweet Corn (Zea mays L.) Hybrids That Differ in Susceptibility to Common Smut Infection of Ears
}

\author{
Jerald K. Pataky ${ }^{1}$ \\ Department of Crop Sciences, University of Illinois, Urbana, IL 61801
}

\author{
Paul M. Richter \\ General Mills Agriculture Research, Le Sueur, MN 56058
}

Additional index words. corn smut, smut resistance, Ustilago maydis, Ustilago zeae

\begin{abstract}
Host resistance is the most efficient way to control common smut (Ustilago maydis) in sweet corn, but resistance to $U$. maydis is not understood well. All meristematic tissues are susceptible, but infection is localized. Ear galls result from infection of ovaries. Infection and resistance can be affected by plant morphology. For example, ovaries are protected from $U$. maydis infection when an abscission zone forms at the base of the silk 6-24 $\mathrm{h}$ after a pollen tube reaches an ovary. The objective of this study was to determine if the rate of silk abscission differed between two related sweet corn hybrids that differed in susceptibility to smut infection of ears. The two hybrids, Green Giant Code 3 (GG3) and Green Giant Code 46 (GG46), were evaluated for the occurrence of infected ears in 58 paired plots at four locations near Le Sueur, MN, from 1993 to 1999 . The rate of silk abscission in the two hybrids was evaluated in two field trials in Urbana, IL, in 2002 and 2004. Incidence and severity of ear smut were significantly $(P<0.05)$ greater and about twice as much on GG3 than on GG46. Silk abscission was more rapid on GG46 than on GG3. Although this association does not prove that decreased susceptibility of GG46 to ear infection is due to silk abscission, it is a logical basis from which to hypothesize that silk dynamics and other aspects of maize floral biology play important roles in resistance to ear infection by minimizing the time period that all ovaries on an ear are exposed to infection by $U$. maydis. This hypothesis is discussed in relation to the results of this and other research.
\end{abstract}

Common smut, incited by Ustilago maydis (DS) Corda (syn. = Ustilago zeae Ung.), reduces the number of marketable ears and adds to the cost of harvesting and processing sweet corn. All meristematic tissues are susceptible to $U$. maydis, but infection is local (i.e., the host is not colonized systemically by the fungus). Plant parts (e.g., leaves, stalks, nodal shoots, tassels, ears) on which galls form depends on which meristematic tissues are active and exposed to the fungus when environmental conditions are favorable for infection (Christensen, 1963). Galls that form on ears are the result of infection of ovaries and have the greatest economic consequences in sweet corn.

U. maydis infection hyphae penetrate and colonize silks, growing toward ovaries in a manner like pollen tubes (Snetselaar and Mims, 1993; Snetselaar et al., 2001). Several pollen tubes may be found in a silk, but only one reaches the ovule and effects fertiliza-

\footnotetext{
Received for publication 15 Feb. 2007. Accepted for publication 25 Mar. 2007.

We thank L.J. du Toit, Washington State Univ., for valuable suggestions and comments on drafts of this paper.

${ }^{1}$ To whom reprint requests should be addressed; e-mail j-pataky@uiuc.edu
}

tion. An abscission zone forms at the base of the silk within 6-24 h after the first pollen tube reaches an ovary (Heslop-Harrison et al., 1985). Cells collapse, and tissue is disorganized in the abscission zone. This region prevents multiple pollen tubes from reaching the ovary. Infection hyphae of $U$. maydis also are restricted by the abscission layer (Snetselaar et al., 2001). When silks senesce because of age, tissues at the base of the silk also collapse, which obstructs pollen tubes and $U$. maydis infection hyphae (Bassetti and Westgate, 1993; Snetselaar et al., 2001). Thus, pollination and maturation of silks render ovaries less susceptible to infection by $U$. maydis and reduce the incidence of ear galls (du Toit and Pataky, 1999; Pataky and Chandler, 2003; Snetselaar et al., 2001).

Host resistance is the most efficient way to control common smut, but resistance to $U$. maydis is not understood well despite over 90 years of breeding. Most double-cross hybrids grown in the 1930s and early 1940s were distinctly more resistant to common smut than open-pollinated varieties grown previously (Stringfield and Bowman, 1942), but genes that control resistance and specific mechanisms of resistance have not yet been documented clearly. Some forms of resistance to $U$. maydis appear to be conditioned by plant morphology. Upon self-fertilizing open-pollinated varieties, early corn breeders rapidly developed inbred lines with noticeably different reactions to common smut (Garber and Quisenberry, 1925; Hayes et al., 1924; Immer and Christensen, 1925; Jones, 1918). Not only did these initial inbreds differ in incidence of infected plants, susceptible inbreds also could be differentiated by the plant parts on which galls occurred. Griffiths (1928) observed that inbred lines resistant to natural infection by $U$. maydis in field trials were very susceptible when sporidial suspensions were injected into young plant tissues. She hypothesized that resistance or susceptibility was largely a matter of relative accessibility of susceptible plant tissues to the invading fungus. Other pathologists and breeders soon made similar observations (Eddins, 1929; Kyle, 1929, 1930; Walter, 1934, 1935). Hoover (1932) concluded that smut reactions probably were controlled by two sets of genetic factors: one controlling physiological behavior, and one concerned with morphology of the plant.

Recently, several quantitative trait loci (QTL) have been associated with resistance to U. maydis and mapped in different maize populations to several chromosomal locations (Baumgarten et al., 2004; Kerns et al., 1999; Lubberstedt et al., 1998; Murua et al., 2006; Parisseaux and Bernardo, 2004). In some populations, QTL were associated with a lower incidence of $U$. maydis galls in specific plant tissues, such as the tassels or ears (Baumgarten et al., 2004; Kerns et al., 1999). In other studies, QTL were associated with a lower incidence of smut-infected plants arising from natural infection of multiple plant parts (Lubberstedt et al., 1998; Parisseaux and Bernardo, 2004). Possibly, some of these QTL are associated with resistance resulting from plant morphological features while others may be associated with physiological factors.

Response to natural infection by $U$. maydis has been the primary basis by which corn lines have been classified as resistant or susceptible to smut. Natural infection also is the primary selection criterion used to eliminate smut-susceptible lines in breeding programs. Selection against smut susceptibility has resulted in field corn hybrids with levels of resistance that are adequate to prevent catastrophic smut epidemics in the United States. Nevertheless, classification of smut reactions based on data from naturally infected trials often is unreliable because host growth stage (i.e., active meristematic tissues) determines which plant tissues are infected during favorable periods. In turn, favorable periods for infection are determined by the fortuitous occurrence of weather conditions (i.e., presumably wind and rain) that promote sporulation and dissemination of $U$. maydis teliospores and sporidia. Thus, reactions that appear to be associated with resistant or susceptible phenotypes based on natural infection may be the result of host maturity at the time of infection. For example, incidence of ear galls was $41 \%$ and $0 \%$ in two adjacent plots of 750 plants of 
a susceptible sweet corn hybrid, 'Candy Bar', planted $12 \mathrm{~d}$ apart in Urbana, IL, in 1989. Incidence of tassel galls in the two plantings was $9 \%$ and $24 \%$, respectively (J.K. Pataky, unpublished). Because the two plantings were at different growth stages when infection occurred, one appeared to be highly susceptible to ear infection and more resistant to tassel infection while the other appeared to be resistant to ear infection and more susceptible to tassel infection. Attempts to classify hybrids for reactions to ear smut following inoculation of silks with U. maydis also have yielded inconsistent results partly due to variability associated with maturity (Pataky et al., 1995).

Because ear galls result from infection of ovaries via colonization of silks, morphological features that protect ovaries from infection may be a mechanism of resistance to $U$. maydis. Maize lines in which silk abscission occurs rapidly after silk emergence may be more resistant to ear galls than lines in which abscission proceeds more slowly. The objective of this study was to determine if the rate of silk abscission differed between two related sweet corn hybrids that differed in susceptibility to smut infection of ears.

\section{Materials and Methods}

Smut reactions and maturity of hybrids. Two related sweet corn hybrids were evaluated in 58 paired plots at four locations near LeSueur, MN, from 1993 to 1999. Four to 12 trials were planted each year from 30 Apr. to 11 June. The hybrids, 'Green Giant Code 3' (GG3) and 'Green Giant Code 46' (GG46), have one inbred parent in common. On the basis of observations in production fields, GG3 and GG46 were considered to be smutsusceptible and smut-resistant, respectively. Each trial included adjacent plots of both hybrids. Plots included 28-32 plants of each hybrid. Twelve trials each included two replicate plots of each hybrid. Forty-eight trials each included two replicate harvests (i.e., different dates) of each hybrid. Ears were harvested at prime canning stage and $2 \mathrm{~d}$ before prime canning stage. In each trial, the percentage of ears with common smut was measured from all ears of each hybrid at each harvest. Mean incidence (\%) of smut was calculated for each hybrid in each trial. Maturity of the two hybrids was determined by heat units accumulated for each hybrid at each harvest. Heat units were calculated as the sum of the average daily temperature greater than $49^{\circ} \mathrm{F}$.

The two hybrids were compared for incidence $(\%)$ of infected ears over all trials (proportion of trials in which smut occurred) by a binomial test of percentages $(\mathrm{n}=58, P<$ $0.05)$. Paired $t$ tests $(P<0.05)$ were used to compare hybrids for severity (\%) of infected ears in all trials, severity in trials in which smut occurred $(\mathrm{n}=32)$, and heat units until harvest. A $t$ test $(P<0.05)$ was used to compare hybrids for severity of infected ears in the $25 \%$ of all trials $(n=14)$ with the highest severity of smut for each hybrid.
Rate of silk abscission. Trials were planted 22 May 2002 and 10 May 2004 at the University of Illinois South Farm, Urbana, IL. In 2002, two replicates of GG3 and GG46 were planted in 12-row plots that were $18.3 \mathrm{~m}$ long with $\approx 90$ plants per row. In 2004, two replicates of GG3, GG46, and five other sweet corn hybrids (GH2690, 'Jubilee', 'Legacy', 'Marvel', and 'Supersweet Jubilee Plus') were planted in 8-row plots that were $46.9 \mathrm{~m}$ long with $\approx 225$ plants per row. Rows were spaced $0.76 \mathrm{~m}$ apart. As soon as tassels emerged from whorls, all plants were inspected every 1 or $2 \mathrm{~d}$ for emergence of silks from ear shoots. Color-coded tags were stapled around plant stalks near tassels to identify the day on which silks first emerged. After 10 or 12 d in 2002 and 2004, respectively, ears from plants with silks emerged for 0-10 d were sampled from each plot. Sample size varied from 40 to 150 ears per plot $(\mathrm{n}=$ 84 to 284 per treatment). Husk leaves were carefully slit longitudinally with a razor, and husks were then removed leaf by leaf so as not to disturb silks. Ears were held by the tip and ear shank and shaken gently 6-10 times to remove silks that were no longer attached to ovaries. In 2002, each ear was categorized based on a visual estimate of the percentage of silks that remained attached, where categories were $100 \%, 90 \%-99 \%, 67 \%-90 \%$, $33 \%-67 \%, 10 \%-33 \%$, and $<10 \%$. In 2004 , each ear was also rated for the percentage of attached silks although the categories were changed slightly to discern differences near $50 \%$, i.e., $100 \%$, 90\%-99\%, 75\%-90\%, $50 \%-75 \%, 25 \%-50 \%, 10 \%-25 \%$, and $<10 \%$. Midpoints of each interval were used to calculate the mean percentage of silks attached for each sample. Hybrids were compared by regressions of percentage of silks attached on days after silk emergence. Distributions of categorized ears also were compared by $\chi^{2}$ test of independence $(P<0.05)$ between hybrids at 2 and $4 \mathrm{~d}$ after silks emerged.

\section{Results}

Smut reactions and maturity of hybrids. Ears galls occurred on one of the two hybrids in 32 of 58 trials. Incidence and severity of ear smut were significantly greater $(P<0.05)$ and about twice as much on GG3 than on GG46 (Table 1). Smut was about twice as frequent $(47 \%$ vs. $28 \%)$ on GG3 than on GG46. The percentage of infected ears per trial (i.e., severity of smut) ranged from $0 \%$ to $37.5 \%$ for GG3 and from $0 \%$ to $10.5 \%$ for GG46. Over all trials, a mean severity of $2.8 \%$ for GG3 was significantly $(P<0.05)$ greater than a mean severity of $1.1 \%$ for GG46 (Table 1). Likewise, in the 32 trials in which smut occurred, a mean severity of $5 \%$ for GG3 was significantly $(P<0.05)$ greater than the $1.9 \%$ mean severity for GG46 (Table 1 ). When the worst 14 trials (worst quartile) for each hybrid were compared, smut was significantly $(P<0.05)$ more severe on GG3 than on GG46, $9.9 \%$ and $4.2 \%$, respectively (Table 1). In 10 of the 58 trials, severity of smut was at least $3 \%$ greater on GG3 than on GG46; however, in two trials, smut severity was at least $5 \%$ greater on GG46 than on GG3. Heat degree days until harvest did not differ significantly $(P=0.12)$ between GG3 and GG46 (Table 1).

Rate of silk abscission. Silk abscission was more rapid on GG46 than GG3 (Figs. 1 and 2). In both trials, the relationship (i.e., regression) between mean percentage of silks attached and silk maturity (days after first silk emergence) differed significantly between GG46 and GG3. Based on comparison of the predicted values from regressions, silk abscission in GG46 occurred $\approx 2-4 \mathrm{~d}$ earlier than in GG3 in 2002 and $\approx 2 \mathrm{~d}$ earlier in 2004 (Figs. 1 and 2). In 2002, 80\% of the ears of GG3 had more than two-thirds of the silks attached 2-3 d after silk emergence compared with $50 \%$ of the ears of GG46 (Fig. $3 \mathrm{~A})$. By $4-5 \mathrm{~d}$ after silk emergence, only $5 \%$ of the ears of GG46 had more than two-thirds of the silks attached compared with $48 \%$ of the ears of GG3 (Fig. 3B). The distributions of ears with different percentages of silks attached were not significantly different $\left(\chi^{2}=\right.$ $0.56, P=0.97$ ) between GG46 $2-3 \mathrm{~d}$ after silks emerged and GG3 $4-5 \mathrm{~d}$ after silks emerged. In 2004, 97\% of the ears of GG3 had more than three-quarters of silks attached 2-3 d after silk emergence compared with $62 \%$ of the ears of GG46 (Fig. 3C). By 4 $5 \mathrm{~d}$ after silk emergence, $26 \%$ of the ears of GG46 had more than three-quarters of the silks attached compared with $73 \%$ of the ears of GG3 (Fig. 3D).

Silk abscission was slower on each of five additional hybrids evaluated in 2004 than on GG46 (Fig. 2). Over 25\% of the ears of 'Jubilee' and 'Supersweet Jubilee Plus' had more than three-quarters of silks attached $8 \mathrm{~d}$ after silk emergence. GH2690, 'Legacy', and 'Marvel' had 67\%, 50\%, and 40\%, respectively, of their ears with three-quarters of silks attached $6 \mathrm{~d}$ after silk emergence.

\section{Discussion}

The rate of silk abscission was different between two related sweet corn hybrids that differed in susceptibility to ear infection by U. maydis. Silks of GG3, a hybrid with a

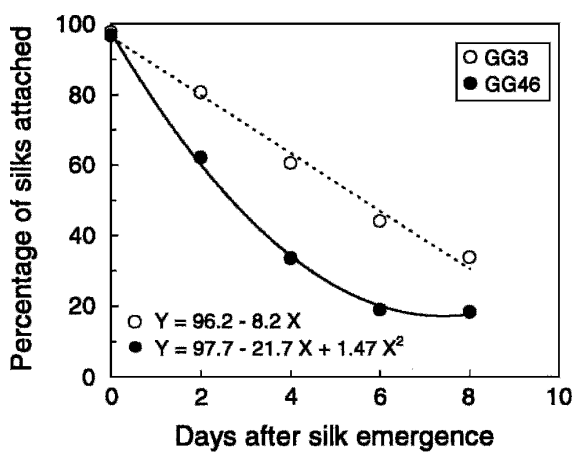

Fig. 1. Percentage of silks attached $0-8 \mathrm{~d}$ after silks first emerged on sweet corn hybrids GG3 and GG46 in field trials in Illinois in 2002. 


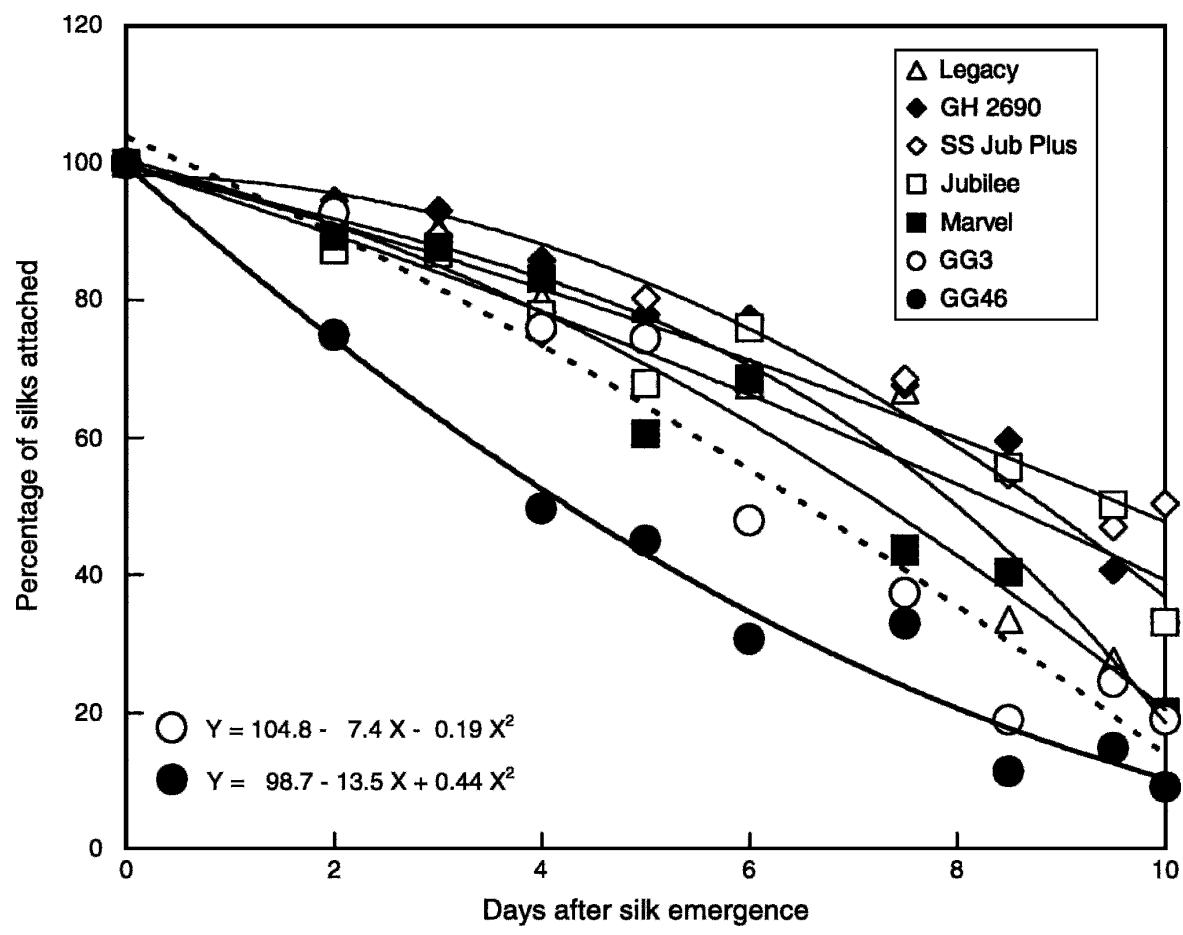

Fig. 2. Percentage of silks attached $0-10 \mathrm{~d}$ after silks first emerged on seven sweet corn hybrids including GG3 and GG46 in field trials in Illinois in 2004. higher amount of $U$. maydis infection of ears, were attached for $\approx 2-4 \mathrm{~d}$ longer than silks of GG46, a hybrid with a lower amount of $U$. maydis infection. This association does not prove that decreased susceptibility of GG46 to ear infection was due to rapid silk abscission. However, it is a logical basis from which to hypothesize that silk dynamics play an important role in resistance to infection of ovaries by $U$. maydis.

Snetselaar et al. (2001) demonstrated clearly that ovaries are protected from $U$. maydis infection when an abscission layer forms at the base of silks after fertilization. Similarly, du Toit and Pataky (1999) and Pataky and Chandler (2003) have shown that infection of ears is affected adversely by pollination and silk maturation. Other aspects of maize floral biology that result in greater uniformity of silk emergence, synchrony of silk emergence and pollen production, and rapid abscission of silks also may reduce ear galls of common smut by minimizing the time period that ovaries on an ear are exposed to infection by $U$. maydis.

Maize silks emerge in a well-defined pattern (Bassetti and Westgate, 1993). The first silks to emerge are from the base of the ear. These are followed by silks from progressively younger flowers in acropetal sequence. This pattern was similar for two
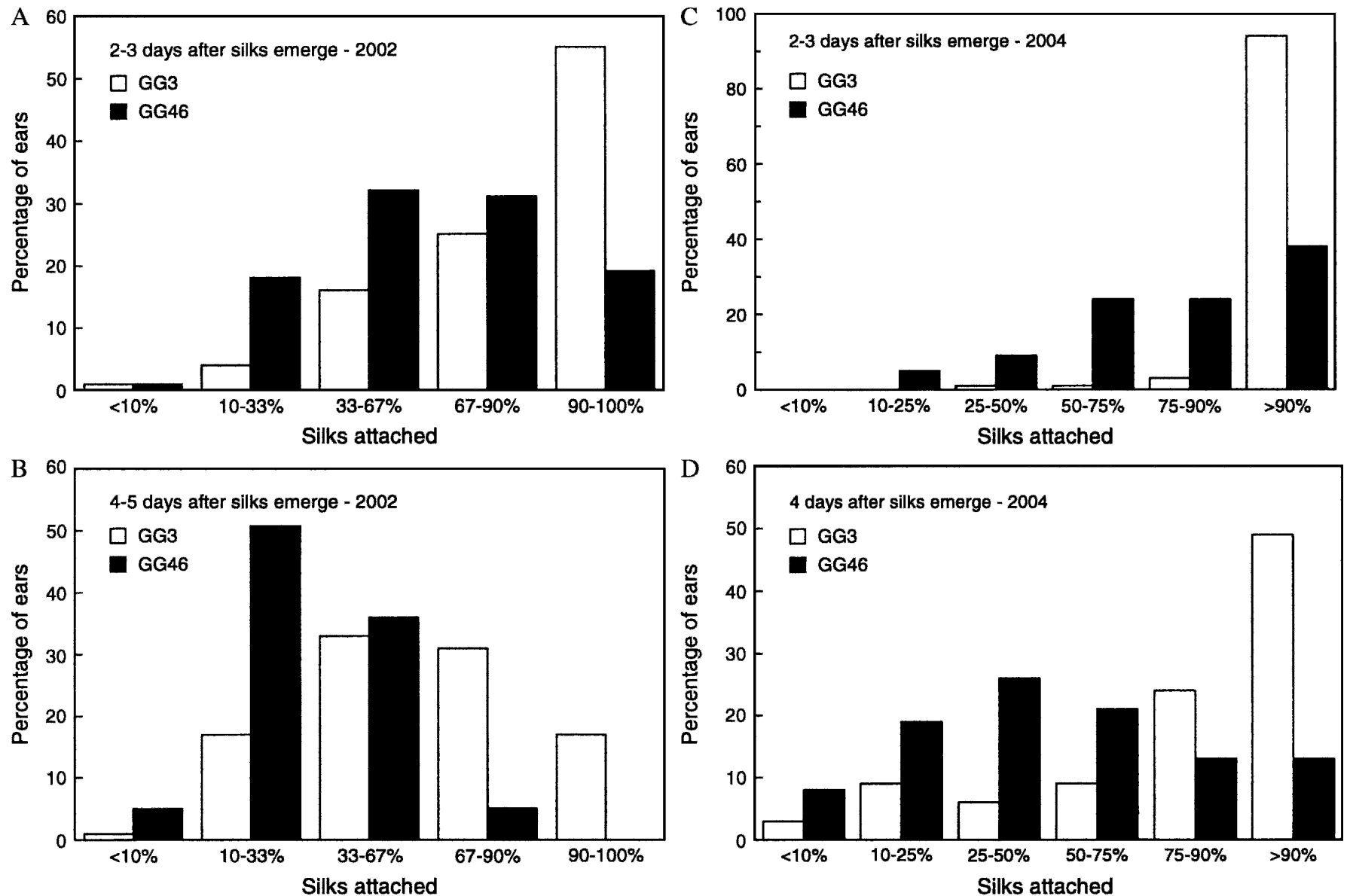

Fig. 3. Distributions of ears of sweet corn hybrids GG3 and GG46 with different percentages of silks attached: (A) 2-3 d after silks emerged in 2002, (B) 4-5 d after silks emerged in 2002, (C) 2-3 d after silks emerged in 2004, and (D) 4 d after silks emerged in 2004. 
Table 1. Heat degree days, ${ }^{\mathrm{z}}$ incidence, ${ }^{\mathrm{y}}$ and severity $^{\mathrm{x}}$ of common smut on ears of two related sweet corn hybrids, GG3 and GG46, grown in 58 paired trials planted from $30 \mathrm{Apr}$. to 11 June at four locations in Minnesota from 1993 to 1999.

\begin{tabular}{lrr}
\hline Variable and comparison & GG3 & GG46 \\
\hline $\begin{array}{l}\text { Heat degree days } \\
\quad \text { until harvest }\end{array}$ & 1778 & $1767^{\mathrm{w}}$ \\
Incidence (\%) of smut & 47 & $28^{\mathrm{v}}$ \\
$\begin{array}{l}\text { Severity of smut } \\
\quad \text { All trials }(\% ; \mathrm{n}=58)\end{array}$ & 2.8 & $1.1^{\mathrm{u}}$ \\
$\quad \begin{array}{l}\text { Trials with smut } \\
\quad(\% ; \mathrm{n}=32)\end{array}$ & 5.0 & $1.9^{\mathrm{u}}$ \\
$\quad$ Worst $25 \%(\% ; \mathrm{n}=14)$ & 9.9 & $4.2^{\mathrm{t}}$ \\
\hline
\end{tabular}

${ }^{\mathrm{z}}$ Heat degree days until harvest $=$ sum of average daily temperatures above $49^{\circ} \mathrm{F}$

${ }^{\mathrm{y}}$ Incidence of smut $=\%$ of trials in which any smut was observed on ears regardless of severity.

${ }^{x}$ Severity of smut $=\%$ of ears in a trial that were infected.

wMean heat degree days for GG3 and GG46 was not significantly different $(P=0.12)$ based on paired $t$ tests.

vIncidence of smut in trials was significantly different $(P<0.05)$ for GG3 and GG46 based a binomial test of percentages.

"Mean severity of smut on GG3 and GG46 was significantly different $(P<0.05)$ based on paired $t$ tests.

${ }^{\mathrm{t}}$ Mean severity of smut on GG3 and GG46 was significantly different $(P<0.05)$ based on a $t$ test of percent severity from the 14 trials in which smut was most severe on each hybrid individually.

field corn hybrids (Pioneer Brand 3790 and Pioneer Brand 3372), but the rate of silk emergence differed dramatically between the two hybrids (Bassetti and Westgate, 1993). All silks of Pioneer 3790 were exposed within $4 \mathrm{~d}$, whereas $8 \mathrm{~d}$ were required for all silks of Pioneer 3732 to be exposed. Rate of silk elongation and the development of an abscission layer at the base of silks of unpollinated ears also differed between these two hybrids. Differences in silk abscission that we observed between the sweet corn hybrids GG3 and GG46 may be due to various combinations of silk emergence, silk elongation, and formation of an abscission layer. Similarly, some of the recently identified QTL associated with smut resistance (Baumgarten et al., 2004; Kerns et al., 1999; Lubberstedt et al., 1998; Murua et al., 2006; Parisseaux and Bernardo, 2004) may affect various aspects of maize floral biology that results in a reduced exposure period for ovaries to be infected.

After observing a negative correlation between husk protection and the number of U. maydis-infected ears, Kyle (1929) hypothesized that resistance to ear smut may be affected by husk protection. Although it is unlikely that husk leaves that form a long, tight silk channel could physically alter the microscopic processes by which $U$. maydis penetrates and colonizes silks, husk leaves may affect silk dynamics and therefore indirectly affect smut infection. The time required for silks to emerge and for pollen tubes to reach ovaries may be longer in hybrids with large husk leaves and longer silk channels. Bassetti and Westgate (1993) noted that emergence of silks from ears with large husk leaves was delayed relative to ears with smaller husks leaves. Differences in GG3 and GG46 observed in our trials also may have been related to uniformity of silk emergence or other factors affected by silk channels formed by husk leaves.

Silk abscission did not differ substantially among the five additional hybrids evaluated in our trials in 2004. Two of these hybrids, 'Jubilee' and 'Supersweet Jubilee', were grouped with seven hybrids with the highest percentage ear infection among 41 hybrids evaluated in at least two of six trials in the Pacific Northwest from 1999 to 2004 (Clough and Hamm, 2005). 'Legacy' and 'Marvel' were grouped with 16 hybrids with the lowest percentage of ear infection in these trials. Possibly, silk dynamics and silk abscission are unrelated to the smut resistance or susceptibility of these hybrids, or conversely, the amount of ear galls observed on these hybrids in the trials from 1999 to 2004 were confounded with factors other than host resistance.

Two anecdotal observations from our trials illustrate the type of inconsistent data that often can be associated with natural occurrence of smut even when the maturity of hybrids is similar. Although nearly twice as much ear smut occurred on GG3 than on GG46 and maturity (based on heat units) was not significantly different between the two hybrids, severity of smut was at least 5\% greater on GG46 than on GG3 in two of the paired trials. In one of those trials, heat units until harvest differed by 40 , thus silk emergence may have differed between the two hybrids. In two other plantings in 1996 in which the hybrids were not paired, severity of smut on GG46 was $>10 \%$. In both of these situations, silks of GG46 must have been at a susceptible stage when wet weather led to the dissemination of $U$. maydis inocula. Although these occurrences of severe smut on GG46 are anecdotal, they illustrate the importance of weather, abundance of inocula, and host maturity in determining the amount and location of smut galls on corn plants.

\section{Literature Cited}

Bassetti, P. and M.E. Westgate. 1993. Emergence, elongation, and senescence of maize silks. Crop Sci. 33:271-275.

Baumgarten, A., J. Suresh, G. May, and R.L. Phillips. 2004. Identification of QTL controlling Ustilago maydis resistance in two recombinant inbred populations. Maize Genet. Conf. Abstr. 46:P147.

Christensen, J.J. 1963. Corn smut caused by Ustilago maydis. Amer. Phytopathol. Soc. Monogr. 2. APS Press, St. Paul, MN.

Clough, G. and P. Hamm. 2005. Cultivar evaluation for control of common smut in sweet corn and high plains virus in the Columbia Basin of Oregon and Washington, p. 105-114. In: 2004 2005 Rpt. to the Agr. Res. Foundation for the Oregon Processed Veg. Commission.

du Toit, L.J. and J.K. Pataky. 1999. Effects of silk maturity and pollination on infection of maize ears by Ustilago maydis. Plant Dis. 83:621626

Eddins, A.H. 1929. Pathogenicity and cultural behavior of Ustilago zeae (Bekm.) Ung. from different localities. Phytopathology 19:885916.

Garber, R.J. and K.S. Quisenberry. 1925. Breeding corn for resistance to smut (Ustilago zeae). J. Amer. Soc. Agron. 17:132-140.

Griffiths, M.A. 1928. Smut susceptibility of naturally resistant corn when artificially inoculated. J. Agr. Res. 36:77-84.

Hayes, H.K., E.C. Stakeman, F. Griffee, and J.J. Christensen. 1924. Reactions of self lines of maize to Ustilago zeae. Phytopathology 14:268-280

Heslop-Harrison, Y., J. Heslop-Harrison, and B.J. Reger. 1985. The pollen stigma interaction in the grasses: VIII. Pollen-tube guidance and the regulation of tube number in Zea mays L. Acta Bot. Neerl. 34:193-211.

Hoover, M.M. 1932. Inheritance studies of the reaction of selfed lines of maize to smut (Ustilago zeae). West Virginia Agr. Expt. Sta. Bul. 253:1-32.

Immer, F.R. and J.J. Christensen. 1925. The reaction of selfed lines and crosses of maize to Ustilago zeae. Phtyopathology 15:699-707.

Jones, D.F. 1918. Segregation of susceptibility to parasitism in maize. Amer. J. Bot. 5:295300 .

Kerns, M.R., J.W. Dudley, and G.K. Rufener, II 1999. QTL for resistance to common rust and smut in maize. Maydica 44:37-45.

Kyle, C.H. 1929. Relation of husk covering to smut of corn ears. U.S. Dept. Agr. Tech. Bul. 120:17.

Kyle, C.H. 1930. Relation between the vigor of the corn plant and its susceptibility to smut (Ustilago zeae). J. Agr. Res. 41:221-231.

Lubberstedt, T., D. Klein, and A.E. Melchinger. 1998. Comparative QTL mapping of resistance to Ustilago maydis across four populations of European flint-maize. Theor. Appl. Genet. 97:1321-1330.

Murua, M., R. Ritchie, M. Gardiner, D. Plaisted, and S. Grier. 2006. QTL mapping of resistance to Ustilago maydis in sweet corn. Maize Genetics Conf. Abstr. 48:P232.

Parisseaux, B. and R. Bernardo. 2004. In silico mapping of quantitative trait loci in maize. Theor. Appl. Genet. 190:508-514.

Pataky, J.K. and M.A. Chandler. 2003. Production of huitlacoche, Ustilago maydis: timing inoculation and controlling pollination. Mycologia 95:1261-1270.

Pataky, J.K., C. Nankam, and M.R. Kerns. 1995. Evaluation of a silk-inoculation technique to differentiate reactions of sweet corn hybrids to common smut. Phytopathology 85:1323 1328.

Snetselaar, K.M. and C.W. Mims. 1993. Infection of maize stigmas by Ustilago maydis: light and electron microscopy. Phytopathology 83:843850 .

Snetselaar, K.M., M. Carfioli, and K.A. Cordisco. 2001. Pollination can protect maize ovaries from infection by Ustilago maydis, the corn smut fungus. Can. J. Bot. 79:1390-1399.

Stringfield, G.H. and D.H. Bowman. 1942. Breeding corn hybrids for smut resistance. J. Amer. Soc. Agron. 14:486-494.

Walter, J.M. 1934. The mode of entrance of Ustilago zeae into corn. Phytopathology 24:1012-1020.

Walter, J.M. 1935. Factors affecting the development of corn smut, Ustilago zeae (Beckm.). Unger. Minn. Agr. Expt. Sta. Tech. Bul. 111. 